\title{
Gli2 mediates the development of castration-resistant prostate cancer
}

\author{
LU XIA ${ }^{1,2}$, HAKIM BOUAMAR ${ }^{1}$, XIANG GU $^{1}$, CARLA ZEBALLOS $^{1}$, \\ TAI QIN ${ }^{1,3}$, BINGZHI WANG ${ }^{1,4}$, YOU ZHOU ${ }^{1}$, YUHUI WANG ${ }^{1,5}$, JUNHUA YANG $^{1}$, \\ HAIYAN ZHU ${ }^{1}$, WEISHE ZHANG ${ }^{2}$, PETER J. HOUGHTON ${ }^{6}$ and LU-ZHE SUN ${ }^{1}$
}

\begin{abstract}
${ }^{1}$ Department of Cell Systems and Anatomy, University of Texas Health Science Center, San Antonio, TX 78229, USA;
${ }^{2}$ Department of Gynecology and Obstetrics, Xiangya Hospital and Xiangya School of Medicine; ${ }^{3}$ Department of Vascular Surgery, Second Xiangya Hospital and Xiangya School of Medicine; Departments of ${ }^{4}$ Urinary Surgery and ${ }^{5}$ General Surgery,

Xiangya Hospital and Xiangya School of Medicine, Central South University, Changsha, Hunan 410008, P.R. China;

${ }^{6}$ Greehey Children Cancer Research Institute, University of Texas Health Science Center at San Antonio, TX 78229, USA
\end{abstract}

Received June 5, 2019; Accepted February 10, 2020

DOI: 10.3892/ijo.2020.5044

\begin{abstract}
Glioma-associated oncogene family zinc finger 2 (Gli2), a key component of the hedgehog signaling pathway, has been previously demonstrated to promote the malignant properties of prostate cancer in vitro. However, the role of Gli2 in the development of castration-resistant prostate cancer (CRPC) has yet to be fully elucidated. In the present study, Gli2 expression was knocked down in androgen-responsive prostate cancer cells using an inducible Gli2 short hairpin RNA. Suppression of Gli2 expression resulted in significant reduction of cell viability, increased the proportion of cells in the $G_{0} / G_{1}$ phases of the cell cycle and reduced the expression of genes associated with cell cycle progression. Gli2 knockdown sensitized both androgen-dependent and -independent prostate cancer cells to the antiandrogen drug Casodex and prevented the outgrowth of LNCaP prostate cancer cells. In addition, Gli2 knockdown significantly suppressed the development of CRPC in a LNCaP xenograft mouse model, which was reversed by the re-expression of Gli2. In conclusion, to the best of our knowledge, the present study was the first occasion in which the essential role of Gli2 in the development of CRPC was demonstrated, providing a potential therapeutic target for the intervention of CRPC.
\end{abstract}

\section{Introduction}

Prostate cancer is one of the most frequently diagnosed malignancies in men. According to a previous report, prostate

Correspondence to: Dr Lu-Zhe Sun, Department of Cell Systems and Anatomy, University of Texas Health Science Center, 7703 Floyd Curl Drive, San Antonio, TX 78229, USA

E-mail: sunl@uthscsa.edu

Key words: prostate cancer, castration-resistant prostate cancer, hedgehog signaling, glioma-associated oncogene family zinc finger 2, mouse xenograft cancer is the third most common cause of death associated with cancer in men in the United States (1). Hormone therapy is frequently applied to treat advanced metastatic prostate cancer $(2,3)$. Although androgen deprivation therapies are effective on the short term, relapse regularly occur shortly following clinical remission due to highly aggressive tumors that are resistant to hormone therapy; this is referred to as castration-resistant prostate cancer (CRPC). The development of CRPC is a complex process that involves reactivation of androgen receptor (AR) signaling (4). Therefore, to improve overall survival, novel strategies in inhibiting the emergence of this phenotype of prostate cancer are urgently needed.

The hedgehog signaling pathway is pivotal to the growth, patterning and morphogenesis of a number of tissues during embryogenesis (5-7). Canonical hedgehog signaling in vertebrates is initiated by the engagement of ligands, including Sonic (Shh), Indian (Ihh) or Desert (Dhh) hedgehog to the Patched (Ptch) receptor on corresponding target cells $(8,9)$, resulting in the dissociation of smoothened (Smo) from the membrane and its activation. The accumulation of active Smo occurs in the primary cilium and induces the processing, re-localization and finally the activation of the glioma-associated oncogene family zinc finger 2 transcription factor (Gli) $(10,11)$.

Although accumulating evidence supports the notion that the hedgehog pathway is involved in the tumorigenesis of a variety of malignancies, including skin, breast, lung, brain, pancreatic, liver, stomach and prostate cancer (12-28), the role of this signaling pathway in prostate cancer remains controversial. Previous evidence supporting this association includes reported findings that prostate cancer cell growth was significantly inhibited by the Smo inhibitor cyclopamine or Gli knockdown $(25,28,29)$. In addition, the expression of components of the hedgehog signaling pathway such as Gli was also found to be is enhanced in the malignant prostate epithelium compared with their benign counterparts $(26,29,30)$. However, by contrast, there remains a lack of evidence for elevated canonical hedgehog signaling activity in commonly used prostate cancer cell lines $(31,32)$. 
Despite its controversial role in the tumorigenesis of prostate cancer, evidence suggests that the canonical autocrine-like hedgehog signaling is reactivated in prostate cancer cells following androgen deprivation $(26,30,33,34)$. Additionally, Gli expression and activity can also be regulated by noncanonical signaling pathways, including Ras- or TGF- $\beta$-mediated signaling (35). In the present study, investigative focus was placed on the role of Gli2, an intracellular mediator of the hedgehog pathway, on CRPC physiology. To the best of our knowledge, the present study was the first in which Gli2 expression was demonstrated to be necessary for the transition of prostate cancer cells from the androgen-dependent to androgen-independent phenotype in vitro and in vivo, suggesting that Gli2 serves as a driver in the progression of prostate cancer to the more severe CRPC.

\section{Materials and methods}

Cell culture. The prostate cancer cell lines LNCaP, 22RV1 and VCaP were originally obtained from American Type Culture Collection (ATCC). LNCaP and 22RV1 were cultured in McCoy's 5A medium supplemented with pyruvate, amino acids, nutrients and 10\% FBS (Gibco; Thermo Fisher Scientific, Inc.) as previously described (34). VCaP cells was grown in RPMI-1640 medium (Invitrogen; Thermo Fisher Scientific, Inc.) supplemented with $10 \%$ FBS and $0.1 \%$ penicillin. Cultures were maintained in $5 \% \mathrm{CO}_{2}$ at $37^{\circ} \mathrm{C}$. These cell lines were authenticated using the DNA markers of short tandem repeats used by ATCC.

Construction of the Tet-inducible Gli2-specific short hairpin RNA(shRNA) expression plasmid. The Gli2 shRNA was cloned into the Tet-pLKO-puro vector for the inducible expression of Gli2 shRNA by doxycycline (DOX). The Tet-pLKO-puro vector was a gift from Dmitri Wiederschain (Addgene plasmid \#21915; http://n2t.net/addgene:21915; RRID:Addgene_21915; Addgene, Inc.) (36). In the absence of doxycycline (DOX-), the Gli2 shRNA expression is repressed by the constitutively expressed TetR protein (36). Upon addition of doxycycline $(\mathrm{DOX}+)$ to the culture medium, this repression is removed and Gli2 shRNA expression is triggered, resulting in Gli2 knockdown.

A number of distinct Gli2-targeting shRNA constructs were designed and cloned into lentiviral vectors, which were then used to transfect LNCaP cells. The efficiency of Gli2 shRNA transfection was determined by measuring Gli2 mRNA levels using reverse transcription-quantitative (RT-qPCR) in transfected LNCaP cells. The most efficient Gli2 shRNA-coding sequence in knocking down Gli2 was chosen and its sequence was as follows: 5'-CCTGGCATG ACTACCACTATG-3'. The sequences of two complementary oligos encoding the Gli2 shRNA were synthesized by Integrated DNA Technologies, Inc.: Forward, 5'-CCGGCC TGGCATGACTACCACTATGCTCGAGCATAGTGGTAGT CATGCCAGGTTTTT-3' and reverse, 5'-AATTAAAAACC TGGCATGACTACCACTATGCTCGAGCATAGTGGTAGT CATGCCAGG-5'. These two complementary oligos were annealed and ligated into the Tet-pLKO-puro vector between the AgeI and EcoRI restriction sites. This recombinant plasmid was named pTet-Gli2shR thereafter. To construct the control vector, the Tet-pLKO-puro vector was first digested with AgeI and EcoRI to release the stuffer segment, following which the 5 ' overhang ends were blunted using DNA Polymerase I, Large (Klenow) Fragment (New England BioLabs, Inc.) where the two blunted ends were ligated using T4 ligase (New England Biolabs, Inc.). This vector was named pTet-ctl thereafter.

Construction of the Gli2 $\Delta N$ expression plasmid. The cDNA sequence for Gli2, obtained from the plasmid pCS2-MT GLI2 FL plasmid, which was a gift from Erich Roessler (Addgene plasmid no. 17648; http://n2t.net/addgene:17648; RRID, Addgene_17648) (37), was used for generating Gli2 $\Delta$ N cDNA, an isoform of Gli2 lacking the 328 amino acid residues in the $\mathrm{N}$-terminal repressor domain. Gli2 $\Delta \mathrm{N}$ cDNA was subsequently cloned into the pSDM101 vector as described previously (38). Briefly, Gli2 $\Delta \mathrm{N}$ expression plasmid was produced by cloning two fragments into the pSDM101 expression vector using the In-Fusion HD Cloning kit according to manufacturer's protocol (cat. no. 011614; Clontech Laboratories, Inc.). The homemade pSDM101 plasmid is a lentiviral vector pWPI backbone, which was a gift from Didier Trono (Addgene plasmid no. 12254; http://n2t.net/addgene:12254; RRID, Addgene_12254), with a linker inserted at the PmeI site to introduce $B a m \mathrm{HI}, M l u \mathrm{I}$ and $N d e \mathrm{I}$ restriction sites. The pSDM101 backbone was digested using the PmeI and BstBI restriction enzymes, where the larger fragment was purified using the EZ DNA Gel Extraction kit (Enzymax, LLC) for use as the vector. The first fragment for the In-Fusion HD Cloning kit, which was part of Gli2 $\Delta N$ cDNA sequence at the $\mathrm{N}$-terminal end, was amplified by PCR using the pCS2-MT GLI2 FL plasmid as template and CloneAmp ${ }^{\mathrm{TM}} \mathrm{HiFi}$ PCR Premix according to manufacturer's protocols (cat. no. 639298; Clontech Laboratories, Inc.). The second fragment, which forms the remaining part of Gli2 $\Delta \mathrm{N}$ cDNA sequence and part of the pSDM101 backbone sequence, was amplified using the pSDM101-Gli2 plasmid as template, which was constructed by cleaving pCS2-MT GLI2 FL using EcoRI and $\mathrm{XbaI}$ restriction enzymes to form the Gli2 cDNA sequence, which was then cloned into the pSDM101 vector via the PmeI site. Primers used for PCR amplification was as follows: Fragment 1 forward, 5'-CTAGCCTCGAGGTTTAAACATGGCCCTCA CCTCCATCA-3', and reverse, 5'-ATAGTAGTGGTCATGCC AGGACACTGGCTGCCT-3'; fragment 2 forward, 5'-CAT GACCACTACTATGAGCCCCCATGCCTGCTA-3' and reverse, 5'-TTGATATCGAATTCGAAGCTTGAGCTCGA-3'. The thermocycling conditions for both $\mathrm{PCR}$ reactions were as follows: 35 cycles of $98^{\circ} \mathrm{C}$ for $10 \mathrm{sec}, 55^{\circ} \mathrm{C}$ for $5 \mathrm{sec}$ and $72^{\circ} \mathrm{C}$ for $15 \mathrm{sec}$. All restriction enzymes mentioned above were purchased from New England Biolabs., Inc.

Stable transfection of plasmids and selection. In total, $2.5 \mu \mathrm{g}$ pTet-Gli2shR or pTet-Ctl plasmids were co-transfected with two packaging vectors, $1.9 \mu \mathrm{g}$ psPAX2 (Addgene, Inc.) and $0.75 \mu \mathrm{g}$ pMD2.G (Addgene, Inc.) into $1.5 \times 10^{6} 293 \mathrm{~T}$ cells using Lipofectamine ${ }^{\circledR} 2000$ (Thermo Fisher Scientific, Inc.) according to manufacturer's protocol, to produce lentiviral particles. The lentiviral particle-containing medium were collected $48 \mathrm{~h}$ after transfection and subsequently added to the culture of the prostate cancer cells at a ratio of $1 \mathrm{ml}$ viral particle-containing medium supplemented with $8 \mu \mathrm{g} / \mathrm{ml}$ 
polybrene to $2 \mathrm{ml}$ DMEM-based culture medium without antibiotics to create prostate cancer cell lines expressing the inducible Gli2 shRNA (LNCaP Gli2shR and 22RV1 Gli2shR) and corresponding controls ( $\mathrm{LNCaP} \mathrm{Ctl}$ and 22RV1 Ctl). The transduced cells were selected using $1 \mu \mathrm{g} / \mathrm{ml}$ puromycin following infection with lentiviral particles. pSDM101 vectors encoding either Gli2 $\Delta \mathrm{N}$ or control (CV) were similarly introduced into LNCaP Gli2shR cells by lentiviral transduction to generate cell lines of LNCaP Gli2shR/Gli2 $\Delta \mathrm{N}$ and LNCaP Gli2shR/CV genotypes, which were selected for using GFP fluorescence.

The lentiviral vector pLKO.1-Gli2 shRNA (Gli2 shR1) and corresponding control vector pLKO.1 were purchased from Sigma-Aldrich; Merck KGaA. These two vectors $(2.5 \mu \mathrm{g})$ were subsequently used to produce lentiviral particles using 293T lentiviral packaging cells in protocols aforementioned and filtered prior to prostate cancer cell transduction. The sequence of Gli2 shR1 used is as follows: 5'-CCGGCTGGACAGGGA TGACTGTAAGCTCGAGCTTACAGTCATCCCTGTCCAG TTTTTG-3'.

MTT cell viability assays. $\mathrm{LNCaP}, 22 \mathrm{RV}-1$ and $\mathrm{VCaP}$ cells were seeded in triplicate at a density of 5,000 cells/well into 96-well tissue culture plates, where they were allowed to adhere for $24 \mathrm{~h}$ and treated with/without $1 \mu \mathrm{M}$ DOX and/or $30 \mu \mathrm{M}$ Casodex ${ }^{\circledR}$ (Sigma-Aldrich; Merck KGaA) at $37^{\circ} \mathrm{C}$ for various indicated time periods. Relative cell viability was quantified by MTT analysis using a protocol described previously (34).

Whole transcriptome sequencing. Prostate cancer cell lines LNCaP Gli2shR and LNCaP Ctl were treated with either DOX or vehicle to generate four conditions with two replicates for each type: i) Ctl DOX; ii) Ctl $\mathrm{DOX}^{+}$; iii) Gli2shR DOX; and iv) Gli2shR DOX+. Total RNA was isolated from the cells using the RNeasy Mini kit according to manufacturer's protocol (Qiagen $\mathrm{GmbH}$ ), following which sequencing libraries were constructed using TruSeq RNA Library Prep kit 2 set B according to manufacturer's protocol (cat. no. RS-122-2002; Illumina, Inc.) and sequenced in a HiSeq ${ }^{\circledR} 2000$ system (Illumina, Inc.) using a single-read 50-bp sequencing protocol. The reads were aligned to the reference human genome (hg19 assembly; University of California Santa Cruz) using TopHat, a spliced read mapper for RNA sequencing (version 2.0.8b) (39). Only $\leq 2$ mismatches were permitted during in the alignment and HTSeq version 0.6.0-count was used to count the gene expression reads (40). R/DESeq (version 1.26.0) (41), DESeq2 (version 1.14.1) (42) and limma (version 3.30.13) (43) were used to identify differentially expressed genes (DEGs) by comparing the two samples from the GLI2shR DOX ${ }^{+}$condition with the other six samples. Significant DEGs were identified using a filter of Bonferroni's correction-adjusted $\mathrm{P} \leq 0.01$ for each package and sequence read abundance per gene $>40 \%$ within each sample/library. The DEGs were defined as the intersected overlapping genes found by all three packages. DEGs were analyzed further for the functional enrichment of gene ontology using the Database for Annotation, Visualization and Integrated Discovery (DAVID) platform $(44,45)$ and Qiagen's Ingenuity ${ }^{\circledR}$ Pathway Analysis (Ingenuity Systems; Qiagen Sciences, Inc.).
Soft agar assay. LNCaP Gli2shR, LNCaP Ctl, 22RV1 Gli2shR and 22RV1 Ctl cells were first resuspended in $250 \mu \mathrm{l}$ $0.4 \%$ agarose supplemented with 5\% FBS and seeded onto a layer of $0.8 \%$ agarose supplemented with $5 \%$ FBS, such that the final cell density was 2,000 cells/well in 24-well tissue culture plates. DOX $(0.1$ or $1 \mu \mathrm{M})$ and/or Casodex $(30 \mu \mathrm{M})$ or DMSO were added five days after seeding, when small colonies could be observed, following which the plates were maintained in an incubator for a further 10-15 days. Colonies were subsequently stained using $1 \mathrm{mg} / \mathrm{ml}$ p-iodonitrotetrazolium violet staining solution (Sigma-Aldrich; Merck KGaA) for 1-2 days in an incubator. All incubations were performed at $37^{\circ} \mathrm{C}$. The plates were scanned using a scanner (Epson Perfection 2450 PHOTO; Seiko Epson Corporation). The colony number in the scanned image of each well with no magnification was quantified using ImageJ software (version 1.8.0; National Institutes of Health).

Analysis of androgen-independent progression of LNCaP cells in vitro. On day $0,1 \times 10^{6} \mathrm{LNCaP} \mathrm{Ctl}$ cells and $\mathrm{LNCaP}$ Gli2shR cells were first seeded into 6-well plates in medium supplemented with 10\% FBS. Following overnight incubation, the medium was changed to an androgen-depleted medium containing 10\% charcoal-stripped FBS (Gibco; Thermo Fisher Scientific, Inc.), where the cells were treated with $1 \mu \mathrm{M}$ DOX or vehicle control. When the Ctl cells reached $90 \%$ confluence, cells were passaged simultaneously using the same ratio (1:3-1:4). All incubations were performed at $37^{\circ} \mathrm{C}$. Phase contrast images of the cells were taken on days 1,10 and 25 following culture using a light microscope (magnification, $\mathrm{x} 40$ ). Cell numbers were counted from five fields of view per condition.

To investigate the association of Gli2 expression with androgen-independent progression in vitro, $1 \times 10^{6} \mathrm{LNCaP}$ cells were first seeded into 6-well plates in DMEM supplemented with $10 \%$ FBS. Following overnight incubation, the medium was changed to an androgen-depleted medium containing 10\% charcoal-stripped FBS supplemented with or without 10 pM synthetic androgen R1881 (cat. no. NLP005; PerkinElmer, Inc.) on day 0. Gli2 expression levels in LNCaP cells were subsequently assessed by reverse transcription-quantitative PCR (RT-qPCR) analysis on days 1, 3, 7, 14 and 21.

Western blot analysis. LNCaP, 22RV1 and VCaP cells were harvested and lysed using a lysis buffer containing $50 \mathrm{mM}$ Tris- $\mathrm{HCl}(\mathrm{pH} 7.4), 150 \mathrm{mM} \mathrm{NaCl}$ and $0.5 \%$ NP-40 supplemented with a protease inhibitor (Thermo Fisher Scientific, Inc.) and a phosphatase inhibitor cocktail $\left(1 \mathrm{mM} \mathrm{Na}_{3} \mathrm{VO}_{4}\right.$, $5 \mathrm{mM} \mathrm{NaF}$ and $20 \mathrm{mM}$ B-glycerophosphate). Total protein concentration was quantified using bicinchoninic acid protein assay (Thermo Fisher Scientific, Inc.) and equal amounts of protein $(20-50 \mu \mathrm{g})$ were separated by $5 \%$ SDS-PAGE, transferred to a nitrocellulose membrane under constant voltage and blocked with 5\% non-fat dried milk dissolved in TBS containing $0.05 \%$ Tween-20 (TBST) at room temperature for $30 \mathrm{~min}$. The membranes were subsequently incubated with primary antibodies at $4^{\circ} \mathrm{C}$ overnight before incubation with secondary antibodies at $4^{\circ} \mathrm{C}$ for $1 \mathrm{~h}$. All primary and secondary antibodies were diluted in TBST supplemented with $3 \%$ milk or BSA (Sigma-Aldrich; Merck KGaA). 
Proteins were visualized by chemiluminescence using Immobilon Western Chemiluminescent HRP Substrate (cat. no. WBKLS0050; EMD Millipore). Primary antibodies against Gli2 (1:200; cat. no. NB600-874; Novus Biologicals, LLC; and cat. no. SC-20291; Santa Cruz Biotechnology, Inc.) and GAPDH (1:5,000; cat. no. 80602-840; Calbiochem; EMD Millipore) and horseradish peroxidase-conjugated secondary antibodies (Goat anti-mouse IgG; cat. no. 115-035-003; 1:4,000; Goat anti-rabbit IgG, cat. no. 111-035-003; 1:3,000; Donkey anti-goat IgG, cat. no. 705-035-003; 1:4,000; all from Jackson ImmunoResearch Laboratories, Inc.) were used for western blotting, in procedures that were described previously (34). The Western blot images were obtained using the FluorChem $^{\mathrm{TM}}$ E imager with AlphaView software version 4.1.4 (ProteinSimple).

Reverse transcription-quantitative PCR (RT-qPCR). RNA was extracted from prostate cancer cells and xenograft tumors using RLT Plus buffer (Qiagen China Co., Ltd.) and RNA binding columns (cat. no. EZCR101; Enzymax, LLC), where the extracted RNA was shredded using a EZshredder column (Enzymax LLC) to remove genomic DNA. Total RNA $(2 \mu \mathrm{g})$ was reverse-transcribed into cDNA using a high-capacity cDNA reverse transcription kit (Invitrogen; Thermo Fisher Scientific, Inc.). The temperature protocol used for reverse transcription was as follows: $25^{\circ} \mathrm{C}$ for $10 \mathrm{~min}$, $37^{\circ} \mathrm{C}$ for $60 \mathrm{~min}$ and $70^{\circ} \mathrm{C}$ for $15 \mathrm{~min}$. Subsequent qPCR was performed using Power SYBR ${ }^{\circledR}$ Green PCR Mix from Life Technologies, Thermo Fisher Scientific, Inc. The thermocycling conditions were as follows: Initial denaturation at $95^{\circ} \mathrm{C}$ for $10 \mathrm{~min}$, followed by 40 cycles of denaturation at $95^{\circ} \mathrm{C}$ for $15 \mathrm{sec}$, annealing at $60^{\circ} \mathrm{C}$ for $15 \mathrm{sec}$ and extension at $70^{\circ} \mathrm{C}$ for $20 \mathrm{sec}$. All primers used in this study were designed using Primer Blast of NCBI and synthesized by Integrated DNA Technologies, Inc. Primer pair specificity was determined by the generation of a single peak on a dissociation curve (melting curve) at the end of RT-PCR cycling program. The relative expression level for each gene was calculated according to the $2^{-\Delta \Delta \mathrm{Cq}}$ method (46), where GAPDH was used as the reference gene. The primer sequences for Gli2 and Gli2 $\Delta \mathrm{N}$ are forward, 5'-GGGTCAACCAGGTGTCCAGCACTGT-3' and reverse, 5'-GATGGAGGGCAGGGTCAAGGAGTTT-3' and GAPDH forward, 5'-GCAGCCTCCCGCTTCGCTC-3' and reverse, 5'-GCGCCCAATACGACCAAATCCGTT-3'.

Cell cycle analysis. Cell cycle analysis was performed with LNCaP Gli2shR and LNCaP Ctl cells. Cells were cultured in medium supplemented with $10 \%$ FBS and treated with $1 \mu \mathrm{M}$ DOX or vehicle for $48 \mathrm{~h}$ before being harvested and incubated with $70 \%$ ethanol overnight at $4^{\circ} \mathrm{C}$ for fixation. The fixed cells were pelleted at $376 \mathrm{x}$ g for $10 \mathrm{~min}$ at room temperature, washed twice with PBS and a DNA staining solution [(PBS, 0.5\% Triton X-100, $50 \mu \mathrm{g} / \mathrm{ml}$ propidium iodide (Sigma-Aldrich; Merck KGaA) and $500 \mu \mathrm{g} / \mathrm{ml}$ RNase A (Worthington Biochemical Corporation)] was added to the cell pellets for resuspension (cell density, $1 \times 10^{6}$ cells $/ \mathrm{ml}$ ). Cells were then incubated at $37^{\circ} \mathrm{C}$ in the dark for $45 \mathrm{~min}$ followed by storage at $4^{\circ} \mathrm{C}$ until analyzed using a BD $^{\text {Tм }}$ LSR II flow cytometer (Becton, Dickinson and Company). FlowJo software (version 7.0; FlowJo LLC) was used to analyze flow cytometry data. Each assay was performed in triplicate.

Animal studies. All mouse experiments were performed in accordance with the appropriate guidelines (47) and were approved by the Institutional Animal Care and Use Committee of the Department of Laboratory Animal Resources at the University of Texas Health Science Center (San Antonio, USA). Animal health and behavior were monitored daily. All xenograft-bearing mice had a single tumor and were euthanized by cervical dislocation after being anesthetized with $2 \%$ isoflurane inhalation before the largest xenograft tumor reached $2 \mathrm{~cm}^{3}$, with a maximal diameter $<2 \mathrm{~cm}$. In total, 40 male (age, 6-8 weeks; weight, 16-20 g) severe combined immunodeficient (SCID) mice were obtained from Taconic Farms Inc. Animals were housed in polycarbonate standard mouse cages $(35 \times 20 \times 15 \mathrm{~cm})$ with wood shavings (Lignocel) as bedding material. Housing conditions were was kept constant (temperature, $18-21^{\circ} \mathrm{C}$; humidity, $40-70 \%$ ) with a 12 -h light/dark cycle. Pelleted mouse food and water was provided ad libitum. LNCaP Gli2shR cells or LNCaP Ctl cells (6x10 cells in $120 \mu \mathrm{l})$, suspended in 50\% Matrigel (Corning Life Sciences) in cold PBS were injected subcutaneously into the right flank of each mouse ( $n=20$ mice per group). After 2-3 weeks, 26 mice with tumor burdens $>100 \mathrm{~mm}^{3}$ (volume $=0.5 \mathrm{x}$ length $\mathrm{x}$ width $^{2}$ ) in volume (16 mice from the $\mathrm{Ctl}$ group and 10 mice from the Gli2shR group) were recruited. In total, six Ctl cell-injected mice were used for measuring Gli2 expression in the xenograft tumors with IHC and the rest of the mice were subdivided into four groups ( $n=5$ mice per group). All 26 mice were surgically castrated to mimic androgen deprivation therapy under anesthesia with $2 \%$ isoflurane inhalation. The mice were kept warm on a heating pad during the surgery. Triple Antibiotic/pain relieving ointment (Mupirocin 2\%; NDC 51672-1354-0; Taro Pharmaceutical Industries, Ltd.) was applied at the surgical site following surgery and during recovery. Buprenorphine $(0.05-0.1 \mathrm{mg} / \mathrm{kg})$ was injected subcutaneously twice a day for two days following surgery for analgesia. A total of 3 mice injected with $\mathrm{Ctl}$ cells were euthanized on day 1 whilst the other 3 mice injected with Ctl cells were euthanized on day 15 following castration. Tumor volume gradually reduced for the following four weeks before DOX treatment was initiated prior to tumor relapse. Castrated mice with tumors were initially administered with drinking water containing 5\% sucrose (for palatability purposes) with or without $1 \mathrm{mg} / \mathrm{ml}$ DOX, which was then reduced to $1.25 \%$ sucrose after six days of treatment for the groups not treated with DOX as the control mice tended to consume too much water, whilst the DOX treatment groups continued receiving 5\% sucrose with $1 \mathrm{mg} / \mathrm{ml}$ DOX. Water was replenished every four days. Tumor size and body weight were measured once every 2-4 days after surgical castration. The development of androgen independence was monitored by the growth of tumors. On day 60 following castration, when a clear difference was observed between the Gli2shR DOX ${ }^{+}$and Gli2shR DOX groups, in addition to the average tumor volume of mice in the Gli2shR DOX- group reaching $1,000 \mathrm{~mm}^{3}$, the experimental endpoint was reached. The mice were euthanized by cervical dislocation following anesthesia with $2 \%$ isoflurane inhalation, following which the tumors were excised. Parts of tumor tissue was then used to for the extraction of RNA for RT-qPCR whilst another part was 

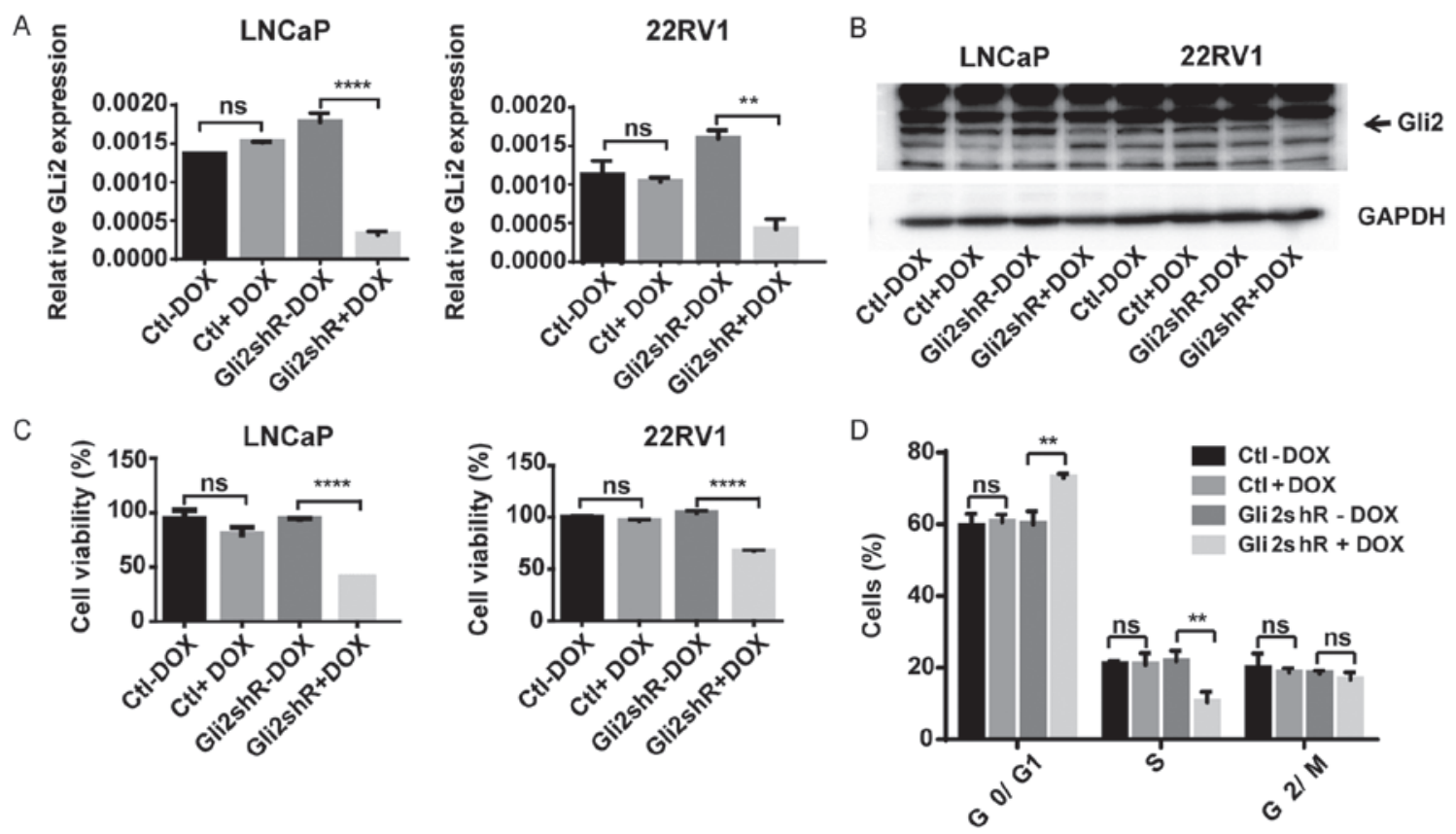

Figure 1. Gli2 knockdown reduces prostate cancer cell viability and induces cell cycle arrest at the $\mathrm{G}_{0} / \mathrm{G}_{1}$ stage. (A) LNCaP Gli2shR, LNCaP Ctl, 22RV1 Gli2shR and 22RV1 Ctl cells were treated without or with $1 \mu \mathrm{M}$ DOX, following which cells were harvested for the measurement of Gli2 mRNA expression using reverse transcription-quantitative PCR and (B) protein expression using western blotting $48 \mathrm{~h}$ after treatment. (C) MTT cell viability assay was performed in LNCaP Ctl, LNCaP Gli2shR, 22RV1 Ctl and 22RV1 Gli2shR cells following treatment with or without $1 \mu$ M DOX for five days. (D) Cell cycle analysis was performed with LNCaP Gli2shR and LNCaP Ctl cells following treatment with or without $1 \mu \mathrm{M}$ DOX for $48 \mathrm{~h}$ by propidium iodide staining. Representative flow cytometry histograms for the plotted data are shown in Fig. S3. Data are presented as the mean \pm SEM from three experimental repeats. ${ }^{* * *} \mathrm{P}<0.01$ and ${ }^{* * * *} \mathrm{P}<0.0001$. ns, not significant; Gli2, Glioma-associated oncogene family zinc finger 2; DOX, doxycycline; Ct1, control vector not encoding the shRNA; Gli2shR, vector encoding Gli2 short hairpin RNA; OD, optical density.

fixed with $10 \%$ formalin for $24 \mathrm{~h}$ at room temperature, which was then replaced with $70 \%$ ethanol until paraffin embedding. Detection of Gli2 and Ki67 expression was performed using immunohistochemistry (IHC) assay.

To investigate tumor response to DOX withdrawal, 6 mice from the LNCaP Gli2shR group $(n=20)$ aforementioned developed tumors later. They were castrated when tumors reached an average volume of $270 \mathrm{~mm}^{3} 2$ months after the inoculation of tumor cells. In total, 8 mice failed to develop tumors or exhibited small tumors (4 in the Ctl group and 4 in the Gli2shR group), which were euthanized at this time. The 6 mice were divided into two groups $(n=3$ per group) with one group receiving $1.25 \%$ sucrose-containing drinking water without DOX and the other group receiving $5 \%$ sucrose-containing drinking water with $1 \mathrm{mg} / \mathrm{ml}$ of DOX starting 3 days after castration. Water was replenished every 4 days. On day 51 following castration, all drinking water was changed to regular water. On day 63 after castration, when the maximum tumor volume reached $1,966 \mathrm{~mm}^{3}$, all three mice in the control group were euthanized, whilst the three DOX-treated mice were euthanized 81 days after castration when tumor growth began to accelerate.

IHC assay. Tissue sections of formalin-fixed and paraffin-embedded tumor tissues were cut into $4.5-\mu \mathrm{m}$ sections using a LEICA RM2255 microtome (Leica Microsystems $\mathrm{GmbH}$ ) and dried at room temperature for $24 \mathrm{~h}$. The sections were then heated to $75^{\circ} \mathrm{C}$ for $15 \mathrm{~min}$ and rehydrated using xylene followed by a descending ethanol series. Antigen retrieval was performed by incubation with a sodium citrate solution $(10 \mathrm{mM}, \mathrm{pH}$ 6.0) or an EDTA solution $(1 \mathrm{mM}, \mathrm{pH} 8.0)$ at $95^{\circ} \mathrm{C}$ for 15 or $30 \mathrm{~min}$, respectively. Sections were then blocked for endogenous peroxidase using 3\% hydrogen peroxide (Thermo Fisher Scientific, Inc.) for $15 \mathrm{~min}$ at room temperature, permeabilized by incubation in $0.3 \%$ TBST for 5 min followed by another incubation in $0.025 \%$ TBST for $5 \mathrm{~min}$ at room temperature and blocked in $10 \%$ goat (Equitech-Bio. Inc.) or donkey (Equitech-Bio. Inc.) serum for $1 \mathrm{~h}$ at room temperature. Primary antibodies against Gli2 (1:200; cat. no. NB600-874; Novus Biologicals, LLC) or anti-Ki67 (1:50; cat. no. 550609; BD Biosciences), diluted in 1X PBS with $0.025 \%$ Triton X-100 and 5\% serum from the species in which secondary antibody was raised were added to the tissue sections followed by incubation at $4^{\circ} \mathrm{C}$ overnight. The sections were then incubated with biotinylated secondary antibodies at room temperature for $1 \mathrm{~h}$ (1:200; cat. nos. 550337 and 550338; BD Pharmingen; BD Biosciences). Streptavidin-Horseradish Peroxidase and DAB Substrate kit (BD Pharmingen; BD Biosciences) were used for the detection of staining under a light microscope (magnification, $\mathrm{x} 40$ ), whilst counterstaining was performed using hematoxylin at room temperature for $2 \mathrm{~min}$.

Statistical analysis. Student's t-test was performed to compare the means of two groups, whereas one-way or two-way ANOVA followed by Tukey's or Sidak's multiple comparisons test was used for analyzing data when the means of $>2$ groups were compared. Results are presented as the mean \pm SEM. $\mathrm{P}<0.05$ was considered to indicate a statistically significant difference. All the statistical analyses 
A

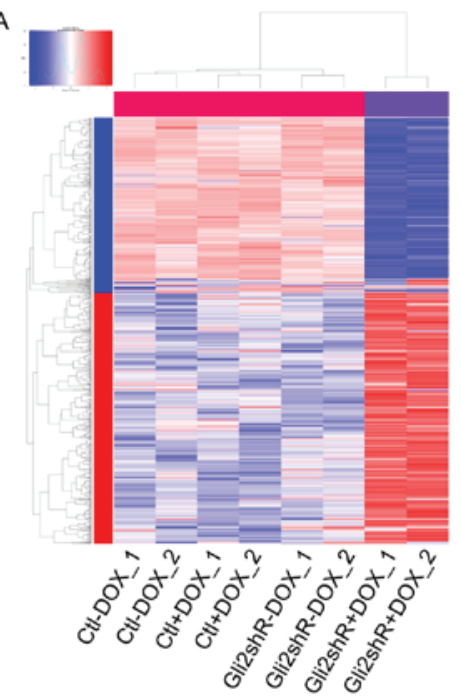

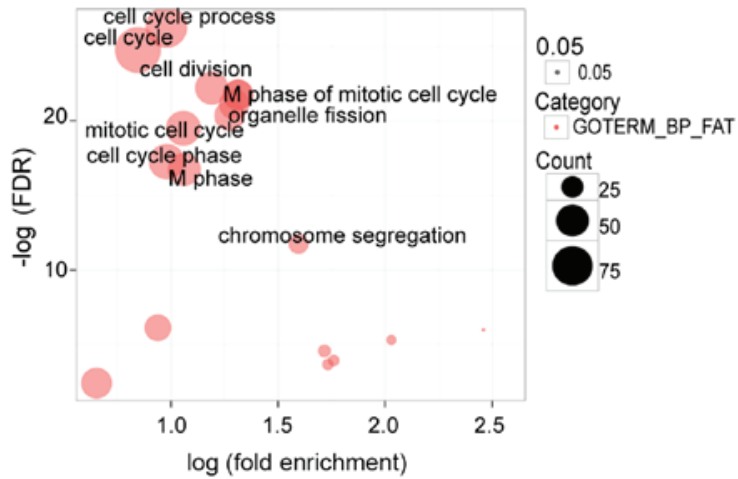

C

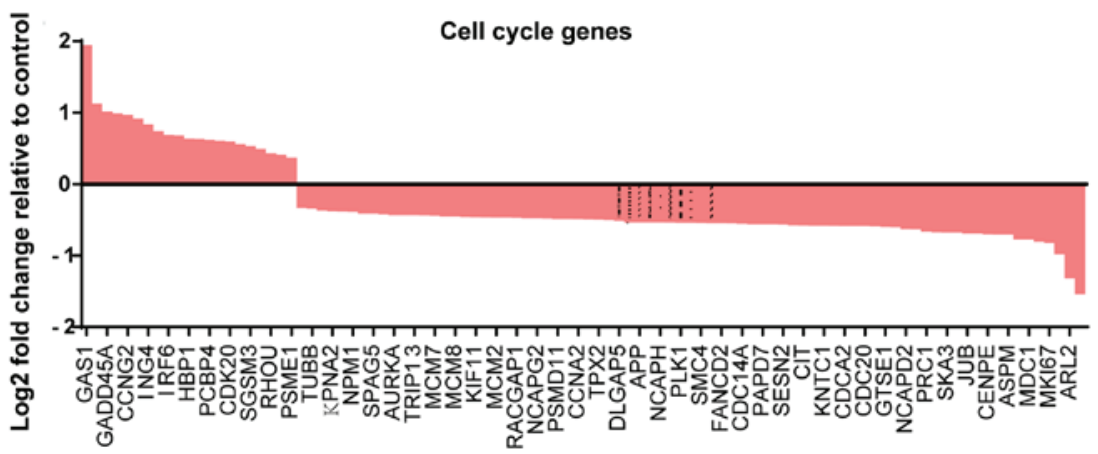

Figure 2. Gli2 serves a significant role in cell cycle regulation. (A) Heatmap showing the significant DEGs following Gli2 knockdown in LNCaP cells. Whole transcriptome sequencing data of cell culture samples from the LNCaP GLI2shR + DOX group were compared against control samples of the other three experimental groups, with each condition performed in duplicate. In the color bar on the left, red indicates genes that are upregulated whereas blue indicates genes that are downregulated upon Gli2 knockdown. In the color bar on the top, the six control samples are marked red whereas the two knockdown samples are marked purple. Expressions of the genes were scaled so that red indicates high expression, whereas blue indicates low expression. (B) Gene Ontology analysis of the DEGs using Database for Annotation, Visualization and Integrated Discovery, which identified the top biological processes that were enriched following Gli2 knockdown. Each circle represents one significantly enriched GO term. The size of each circle is proportional to the number of genes that were enriched for the GO term. (C) $\log _{2} \mathrm{FC}$ of significant DEGs involved in cell cycle. The genes were identified using Qiagen's Ingenuity ${ }^{\circledR}$ Pathway Analysis and ranked by $\log _{2} \mathrm{FC}$ such that upregulated DEGs were on the left and downregulated genes on the right. FC, fold-change; DEGs, differentially expressed genes; Gli2, Glioma-associated oncogene family zinc finger 2; DOX, doxycycline; Ctl, control vector not encoding the shRNA; Gli2shR, vector encoding Gli2 short hairpin RNA; GO, Gene Ontology.

were performed using the Graph Pad Prism 7.0 software (Graphpad Software, Inc.).

\section{Results}

Gli2 knockdown inhibits prostate cancer cell proliferation and induces cell cycle arrest at the $G_{0} / G_{1}$ phase. LNCaP Gli2shR and 22RV1 Gli2shR cell lines were generated by transfection with the pTet-Gli2shR plasmid. Preliminary data in LNCaP Gli2shR cells demonstrated that $1 \mu \mathrm{M}$ DOX treatment induced a marked reduction in Gli2 protein expression (Fig. S1). LNCaP Gli2shR, 22RV1 Gli2shR and corresponding control cells were treated with $1 \mu \mathrm{M}$ DOX for $48 \mathrm{~h}$. Gli2 mRNA and protein expression were both observed to be markedly lower in LNCaP Gli2shR and 22RV1 Gli2shR cells following DOX treatment compared with corresponding control cells (Fig. 1A and B). In addition, treatment of LNCaP Gli2shR and 22RV1 Gli2shR cells with $1 \mu \mathrm{M}$ DOX resulted in significant reductions in cell viability (Fig. 1C). By contrast, cell viability in corresponding control cells was not affected by $1 \mu \mathrm{M}$ DOX treatment (Fig. 1C).
To verify the aforementioned observations, a separate Gli2 shRNA (Gli2 shR1) lentiviral vector was stably transfected into the LNCaP, 22RV1 and $\mathrm{VCaP}$ cell lines, which also resulted in marked reductions in Gli2 expression and significantly reduced cell viability (Fig. S2).

To investigate the effects of Gli2 knockdown on cell cycle progression, LNCaP Gli2shR and $\mathrm{LNCaP} \mathrm{Ctl}$ cells were treated with $1 \mu \mathrm{M}$ DOX or vehicle for $48 \mathrm{~h}$, following which the cells were harvested for cell cycle analysis. Gli2 knockdown resulted in a significantly increased proportion of LNCaP cells in the $\mathrm{G}_{0} / \mathrm{G}_{1}$ phase (Fig. 1D) and a significant reduction of cells in S phase (Figs. 1D and S3). To clarify that this observed growth inhibitory effect is Gli2 specific, a rescue experiment was performed by first stably transfecting LNCaP Gli2shR cells with the Gli2 $\Delta \mathrm{N}$ expression vector or control pSDM101vector (CV), followed by treatment with or without DOX and measurement of cell viability using the MTT assay. Compared with cells transfected with the control vector, Gli2 expression as found to be significantly higher in LNCaP Gli2shR cells transfected with Gli2 $\Delta \mathrm{N}$ (Fig. S4A and B), which also significantly enhanced cell viability in the 

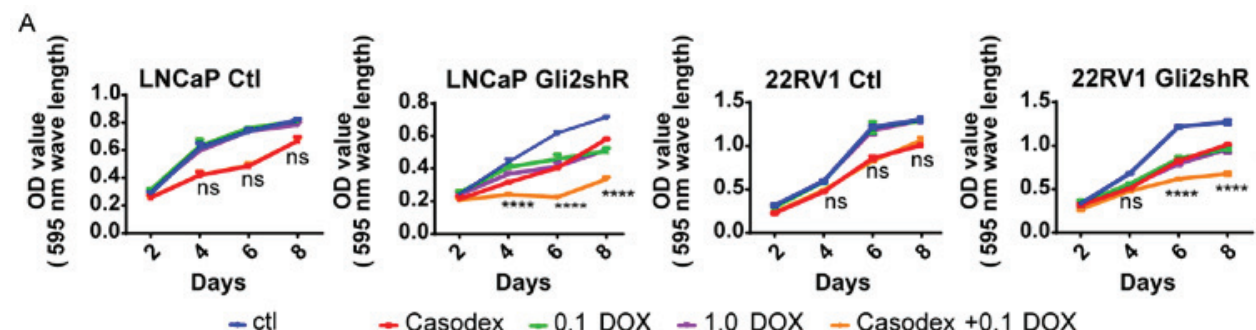

B
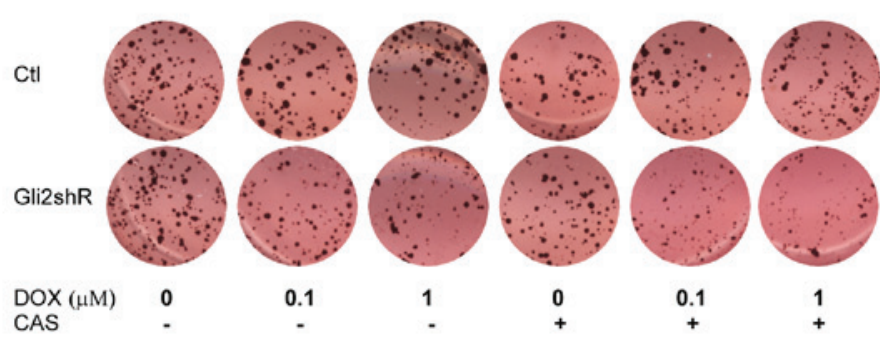

LNCaP

C

LNCaP CtI

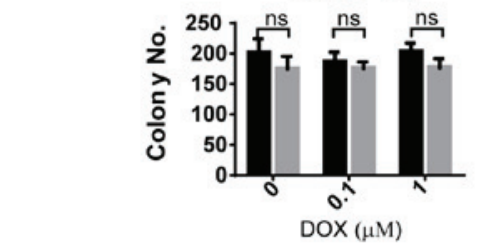

LNCaP Gli2shR

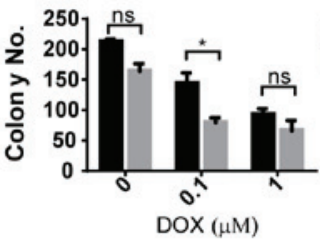

D
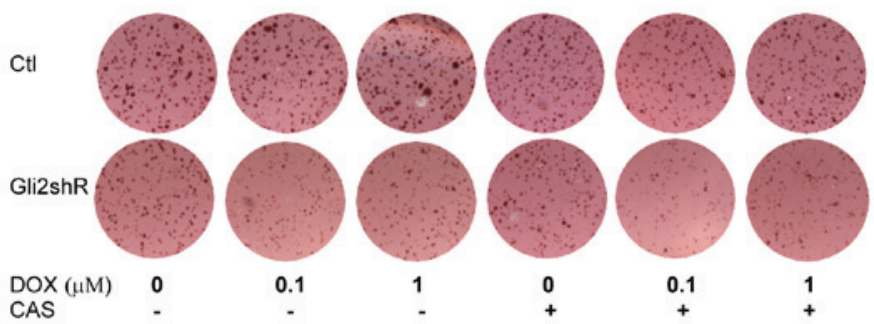

22RV1

$E$

22RV1 Ctl
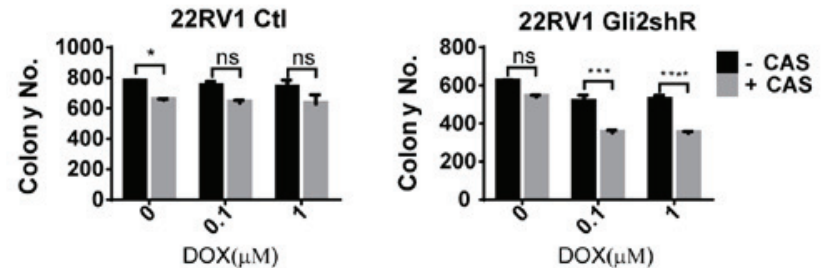

Figure 3. Gli2 knockdown exerts additive inhibitory effects with Casodex in the anchorage-dependent and -independent growth of prostate cancer cells (A) MTT cell viability assay was performed with LNCaP Ctl, LNCaP Gli2shR, 22RV1 Ctl and 22RV1 Gli2shR cells treated with DOX $(0.1 \mu \mathrm{M}$ or $1.0 \mu \mathrm{M})$ and/or $30 \mu \mathrm{M}$ Casodex or equivalent control vehicle, DMSO. Cell viability was measured on days 2, 4, 6 and 8 by measuring absorbance at $595 \mathrm{~nm}$. Data is presented as the mean \pm SEM of absorbance of 3 wells per group. ${ }^{* * * *} \mathrm{P}<0.0001$, Casodex vs. Casodex $+0.1 \mathrm{DOX}$. Soft agar assay was performed with LNCaP Gli2shR, LNCaP Ctl, 22RV1 Ctl and 22RV1 Gli2shR cells following treatment with DOX $(0.1 \mu \mathrm{M}$ or $1.0 \mu \mathrm{M})$ and/or $30 \mu \mathrm{M}$ Casodex. The number of colonies formed were then counted 15-20 days later. (B) Representative images of colonies formed by LNCaP Gli2shR and LNCaP Ctl cells. (C) Quantified data of the images shown in (B). (D) Representative images of colonies formed by 22RV1 Gli2shR and 22RV1 Ctl cells. (E) Quantified data of the images shown in (D). Data is presented as the mean \pm SEM of three experimental replicates. ${ }^{*} \mathrm{P}<0.05,{ }^{* * *} \mathrm{P}<0.001$ and ${ }^{* * * * *} \mathrm{P}<0.0001$. ns, not significant; OD, optical density; CAS, Casodex; DOX, doxycycline; Gli2, Glioma-associated oncogene family zinc finger 2; Ctl, control vector not encoding the shRNA; Gli2shR, vector encoding Gli2 short hairpin RNA.

absence of DOX (Fig. S4C). Following treatment with DOX, LNCaP Gli2shR/Gli2 $\Delta \mathrm{N}$ cell viability was significantly higher compared with cells transfected with the control vector. Therefore, restoration of Gli2 expression reversed the inhibitory effects of Gli2 knockdown on LNCaP cell viability (Fig. S4C). These findings suggest that the cell growth inhibition following Gli2 shRNA transfection was specifically due to Gli2 knockdown.

Transcriptome analysis consolidates the role of Gli2 in cell cycle regulation. Prostate cancer cell lines LNCaP Gli2shR and LNCaP Ctl were treated with either DOX or vehicle such that four experimental groups were formed, each performed in duplicate: i) Ctl DOX; ii) Ctl $\mathrm{DOX}^{+}$; iii) Gli2shR DOX; and iv) Gli2shR DOX'. Total RNA was then isolated from the cell lines from the four groups. Through whole genome RNA sequence analysis, a total of 560 upregulated and 378 downregulated genes were identified following Gli2 knockdown (Fig. 2A), which were observed to be significantly enriched in biological processes associated with cell cycle regulation (Fig. 2B). Specifically, the majority of the DEGs involved in cell cycle regulation were found to be downregulated after 
A
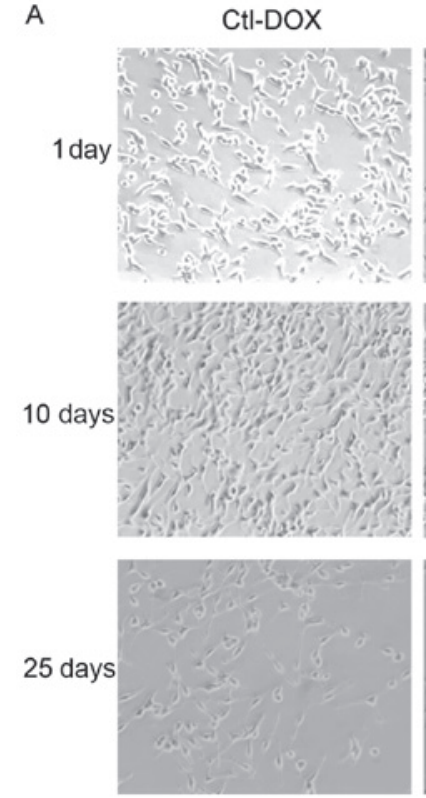

Ct1+DOX
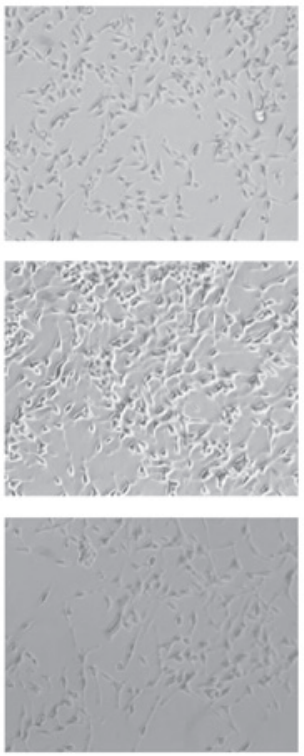

B

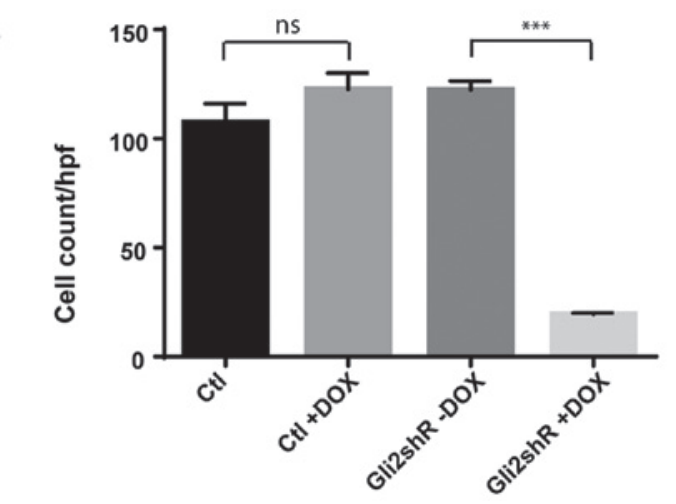

Gli2shR-DOX
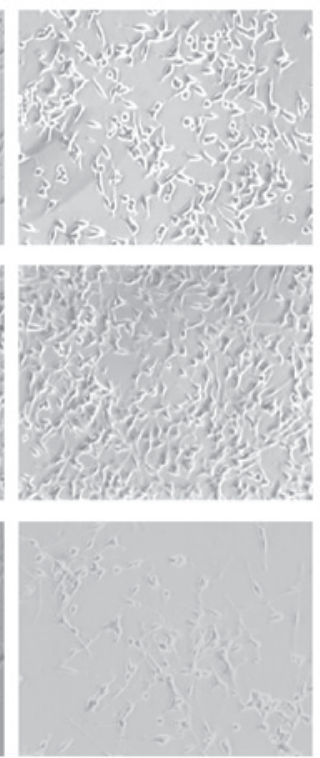

Gli2shR+DOX
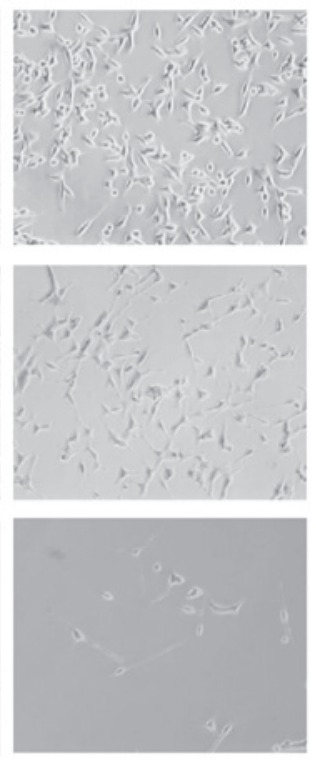

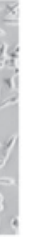

(n) 


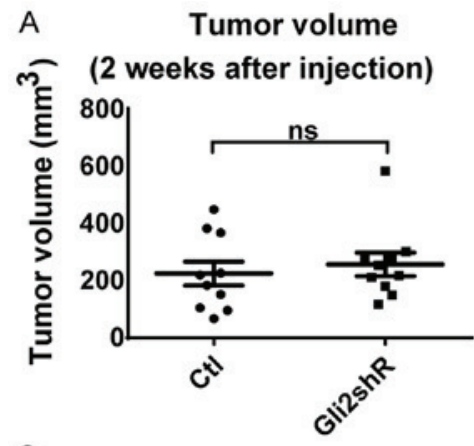

C

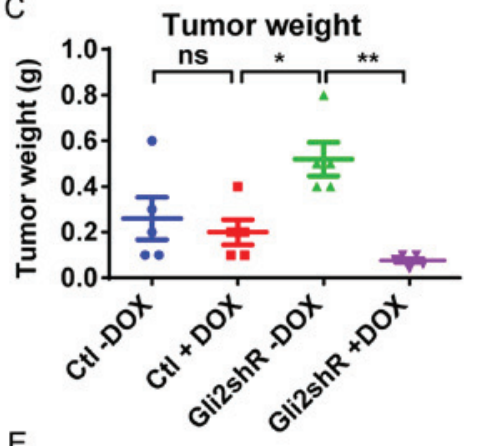

E

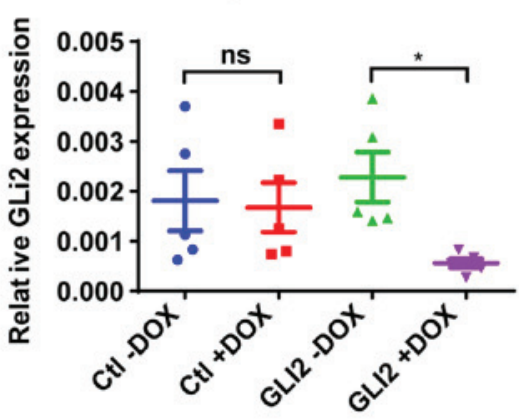

G

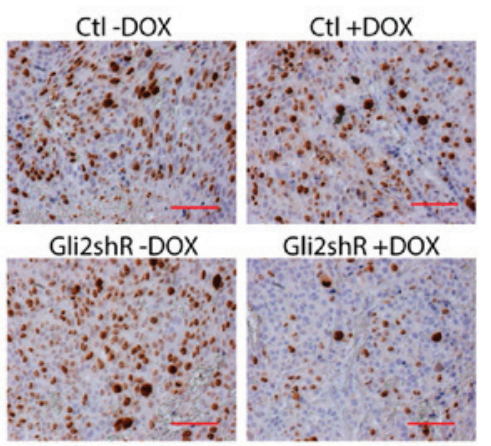

B

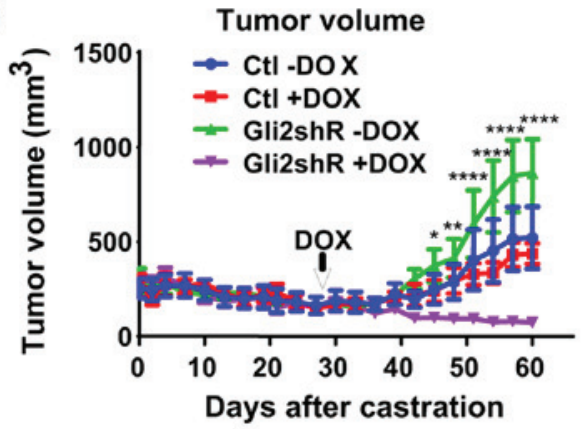

D

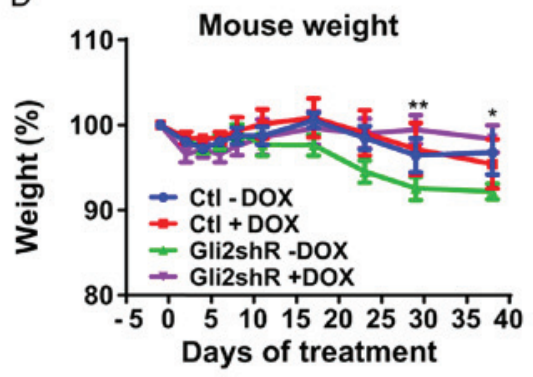

$\mathrm{F}$
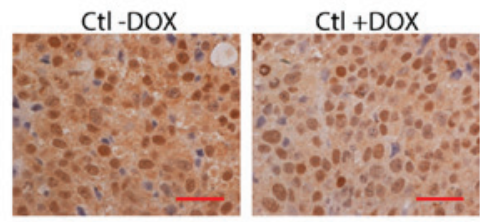

Gli2shR-DOX

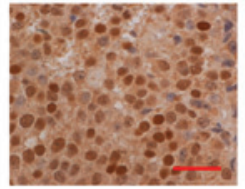

Gli2shR +DOX

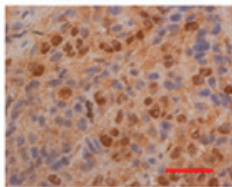

$\mathrm{H}$

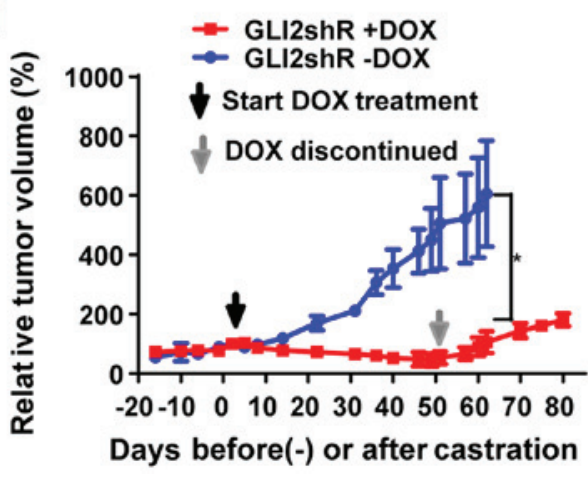

Figure 5. Gli2 knockdown inhibits the growth of castration-resistant tumors in vivo. (A) LNCaP Gli2shR or LNCaP Ctl cells were inoculated subcutaneously into the right flank of male SCID mice ( $\mathrm{n}=20$ mice per group). After 2-3 weeks, mice with a tumor burden $>100 \mathrm{~mm}^{3}$ in volume (volume $=0.5 \mathrm{x}$ length $\mathrm{x}$ width $\left.{ }^{2}\right)$ were recruited into the study groups ( $\mathrm{n}=10$ mice per group). (B) Average tumor volume in the Ctl-DOX, Ctl+DOX, Gli2shR-DOX and Gli2shR+DOX subgroups. Data is presented as the mean \pm SEM of tumors from five mice per group. ${ }^{*} \mathrm{P}<0.05,{ }^{* *} \mathrm{P}<0.01$ and ${ }^{* * * *} \mathrm{P}<0.0001$, GLI2-DOX vs. GLI2+DOX. (C) Final tumor weight was measured 60 days after castration when the mice were euthanized and their tumors were excised. Each dot represents one mouse. ${ }^{*} \mathrm{P}<0.05$ and ${ }^{* *} \mathrm{P}<0.01$. (D) Mouse body weight was monitored following the initiation of DOX treatment. Percentage change in body weight relative to the value obtained on day 0 is presented. Data is presented as the mean \pm SEM from five mice. ${ }^{*} \mathrm{P}<0.05$ and ${ }^{* *} \mathrm{P}<0.01$, GLI2-DOX vs. GLI2+DOX. (E) Gli2 mRNA expression in tumors samples isolated from mice in each subgroup was measured using reverse transcription-quantitative PCR. Each dot represents the quantified value from one tumor sample. "P $<0.05$. (F) Representative images showing Gli2 immunohistochemical staining in tumor tissues isolated from the mice in each of the four groups. Scale bar, $50 \mu \mathrm{m}$. (G) Representative images showing Ki67 immunohistochemical staining in tumor tissues isolated from the mice in each of the four groups. Scale bar, $100 \mu \mathrm{m}$. (H) Tumor volume following DOX withdrawal. The percentage tumor volume relative to the value obtained one day prior to DOX treatment for each tumor was plotted in the figure. Data is presented as the mean \pm SEM of tumor volumes obtained from three mice per group. " $\mathrm{P}<0.05$ between day 40 and 62 after castration. ns, not significant; SCID, severe combined immunodeficient; DOX, doxycycline; Gli2, Glioma-associated oncogene family zinc finger 2; Ctl, control vector not encoding the shRNA; Gli2shR, vector encoding Gli2 short hairpin RNA.

groups after 10 days (Fig. 4A and B), with the difference more notable after 25 days. These observations suggest that androgen deprivation-induced Gli2 upregulation is necessary for prostate cancer transition into androgen-independence. 
For in vivo studies, 16 SCID mice bearing xenograft tumors formed by injection with LNCaP Ctl cells were castrated when the tumors reached an average size of $200-300 \mathrm{~mm}^{3}$. A total of 3 mice were euthanized each on days 1 and 15 after castration, whereas the remaining 10 mice used for with or without DOX treatment with 5 mice in each group, which were euthanized on day 60 (Fig. 5B). Gli2 expression in tumor tissues were measured using immunohistochemical staining. When cultured in an androgen-depleted environment, Gli2 expression in $\mathrm{LNCaP}$ cells was upregulated in a time dependent manner, but not when in the presence of the synthetic androgen R1881 (Fig. S5A), consistent with previous observations $(33,34)$. Gli2 expression was also found to be upregulated in a time dependent manner in LNCaP xenograft tumors following castration, where they became castration resistant (Fig. S5B).

Gli2 knockdown inhibits the growth of castration-resistant tumors in vivo. The effects of Gli2 knockdown on the androgen independence of LNCaP xenografts following castration was next examined in vivo. Male SCID mice were inoculated with either LNCaP Gli2shR or LNCaP Ctl cells mixed with Matrigel, following which they were castrated when tumors reached an average volume of $200-300 \mathrm{~mm}^{3}$ two weeks after injection (Fig. 5A).

Following castration, mice were subdivided into two groups, where one group were provided with drinking water supplemented with DOX, whilst the other was provided with drinking water without DOX. Mice from all groups exhibited tumor relapse 40 days after castration (Fig. 5B), but mice in the LNCaP Gli2shR DOX ${ }^{+}$group displayed continuous tumor regression (Fig. 5B). Differences between LNCaP Gli2shR $\mathrm{DOX}^{+}$and LNCaP Gli2shR DOX ${ }^{-}$were notable shortly after DOX treatment, which became significant from day 45 onwards (Fig. 5B). Consistent with the final tumor volume, tumor weights of mice from the LNCaP Gli2shR DOX group was significantly reduced compared with those in the LNCaP Gli2shR DOX group, whilst no significant differences were observed between the two LNCaP Ctl groups (Fig. 5C). Mice from the LNCaP Gli2shR DOX ${ }^{-}$group also exhibited significantly increased loss in body weight compared with the $\mathrm{LNCaP} \mathrm{DOX}^{+}$group (Fig. 5D). Analysis of Gli2 expression in tumor tissues revealed that Gli2 $\mathrm{mRNA}$ and protein expression was markedly lower in the LNCaP Gli2shR DOX ${ }^{+}$ group compared with the LNCaP Gli2shR DOX group (Fig. 5E and F). Immunohistochemistry also revealed reduced $\mathrm{Ki67}$ expression in tumor tissues isolated from mice in the LNCaP Gli2shR DOX ${ }^{+}$group, suggesting reduced LNCaP xenograft cell proliferation in vivo (Fig. 5G).

To investigate tumor response to DOX withdrawal, six mice bearing LNCaP Gli2shR tumors were castrated and divided into two groups three days following castration, with one group receiving DOX and the other without DOX. After a short response to surgical castration, LNCaP Gli2shR DOX tumors quickly relapsed in the 47 days following treatment, but not in LNCaP Gli2shR DOX ${ }^{+}$tumors, (Fig. 5H); significant differences were observed in the tumor volumes between these groups from day 10 after DOX treatment onwards (Fig. 5H). DOX treatment was withdrawn after 47 days, where tumor relapse was observed in both LNCaP Gli2shR groups. In conclusion, these data suggest that the suppression of Gli2 expression can sensitize LNCaP tumors to androgen deprivation, resulting in significant regression of $\mathrm{LNCaP}$ tumors and preventing the progression of androgen-sensitive $\mathrm{LNCaP}$ tumors to castration-resistant tumors in SCID mice.

\section{Discussion}

Accumulating evidence suggest that the re-activation of canonical hedgehog signaling occurs in prostate cancer cells during androgen-deprivation (27,34). In addition, Gli2 expression and activity can be regulated by alternative signaling pathways, including Ras and TGF- $\beta$ signaling (35). Therefore, in the present study, the role of Gli2, a critical component of the hedgehog signaling pathway, in the progression of hormone-naïve prostate cancer to CRPC was studied. Analysis of Gli2 expression in LNCaP tumors in castrated SCID mice showed that castration was associated with Gli2 upregulation. This was consistent with a previous study, which showed that androgen deprivation resulted in increased Shh, Gli2 and Ptch expression in LNCaP cells and other androgen-responsive prostate cancer cell lines in vitro (33). In addition, Narita et al (26) previously compared the Gli2 expression profiles of benign prostate hyperplasia, prostate cancer treated with neoadjuvant hormonal therapy and androgen-independent prostate cancer using a tissue microarray and found that Gli2 expression was significantly higher in prostate cancer compared with benign prostate hyperplasia, which was reduced following androgen ablation in a time-dependent manner; by contrast, Gli2 expression was found to be reactivated in androgen-independent prostate cancer. However, it should be noted that increases Gli2 mRNA expression was not observed when compared between untreated and hormone deprivation therapy-treated prostate cancers in a limited number of gene expression profiling studies $(48,49)$. Given the heterogeneity of gene expression among prostate cancers in humans, the $\leq 20$ samples tested in these two previous paired studies of prostate cancer pre- and post-hormone deprivation therapy is likely to be insufficient, where a larger sample size is required to verify the regulation of Gli2 expression in prostate cancer in humans during hormone deprivation therapy.

One of the novel findings in the present study was that LNCaP tumors with reduced Gli2 expression failed to progress to CRPC following castration-induced androgen deprivation. A previous study targeted Smo using either cyclopamine or siRNA demonstrated in vitro that Hedgehog/Gli signaling supported androgen-independent growth of prostate cancer cells in a low androgen environment (27). However, the role of Gli transcription factors in CRPC progression remains to be fully elucidated. In another previous study, which used PC-3 xenografts as an advanced model of CRPC, found that targeting Gli2 using an antisense oligonucleotide induced CRPC apoptosis (26). An important distinction in the present study is that tumors from LNCaP cells were used in SCID mice as a preclinical prostate cancer model. LNCaP xenografts exhibit similar behavior compared with clinical prostate cancer tumors, since both typically relapse following a temporary remission due to androgen deprivation (50) Therefore, LNCaP xenograft represent a superior model in mimicking the CRPC progression process. A number of studies have previously demonstrated 
increased hedgehog/Smo expression and subsequent signaling activity in hormone deprivation therapy-treated and/or metastatic human prostate cancers, where Gli2 was revealed an important mediator of hedgehog/Smo signaling $(25,30,34)$. In the present study, Gli2 knockdown prevented the formation of CRPC, suggesting the that targeting Gli2 expression in the early stages following hormonal therapy may be beneficial in prolonging relapse-free survival, even though the upregulation of Gli2 mRNA expression after castration in prostate cancer cell lines and xenografts has not been corroborated in human samples.

Despite being androgen-independent, AR signaling remain a pivotal driver in mediating disease progression in CRPC (51,52). Mechanistically, elevated expression of AR signaling coactivators in tumor cells facilitate AR activity in a low androgen environment (53). Previous studies showed that Gli2 can potentially serve as a coactivator of AR, where it interacts with the Tau5/AF-5 N-terminal activation domain of AR, referred to as the androgen-independent activation domain (27,54). Gli2 may also function by supporting androgen signaling in CRPC cells through the coactivation of the full-length AR and its splice variants (54).

Another plausible explanation for the sustained AR signaling may be the prevalence of AR splice variants, which encode truncated versions of the AR protein that lacks the C-terminal ligand binding domain $(4,55)$. These versions of $\mathrm{AR}$ are transcription factors that are androgen-independent and are constitutively activated. The molecular mechanism by which AR splice variants are generated remains unclear. A previous study demonstrated that androgen deprivation therapy increased the rate of AR gene transcription and the recruitment of splicing factors to the AR pre-mRNA, in turn contributing to elevated AR-V7 levels in prostate cancer cells (56). Two RNA splicing enhancers and associated binding proteins (U2 Small Nuclear RNA Auxiliary Factor 65 and Serine and Arginine Rich Splicing Factor 1) were identified to serve critical roles in the splicing of the AR pre-mRNA into AR-V7 (56). Therefore, future studies will be focused on investigating the effects of Gli2 on the expression of AR splice variants under androgen-deprived conditions and associated mechanism in the development of CRPC.

\section{Acknowledgements}

Not applicable.

\section{Funding}

The present study was in part supported by The Cancer Prevention and Research Institute of Texas (grant no. RP120290-IIRA) and National Institutes of Health (grant no. R01CA172886) to LZS, and National Cancer Institute Cancer Center Support Grant to the Shared Resources of Flow Cytometry and Next Generation Sequencing (grant no. P30 CA054174-17). LX, TQ and BZW were in part supported by a fellowship from Xiangya School of Medicine, Central South University, Changsha, Hunan, P.R. China. XG was in part supported by Cancer Research Training Program Grants from The Cancer Prevention and Research Institute of
Texas (grant nos. RP140105 and RP170345). CZ was in part supported by NIH training grants (grant nos. T32CA148724 and F32CA228435).

\section{Availability of data and materials}

The analyzed datasets generated during this study are available from the corresponding author on reasonable request.

\section{Authors' contributions}

LZS made substantial contributions to the conception and design of the study. LX, HB, CZ, TQ, BZW, YHW, JHY and HYZ contributed to the experimental design and performed the experiments, in addition to data analysis and interpretation. $\mathrm{XG}, \mathrm{CZ}$ and $\mathrm{YZ}$ performed the whole transcriptome sequencing analysis. LX and LZS wrote and revised the manuscript. PJH provided the mice for the xenograft experiment and performed the acquisition of data. WZ performed analysis and interpretation of the data. All authors have read and approved the final version of manuscript.

\section{Ethics approval and consent to participate}

All animal experiments were conducted following appropriate guidelines. They were approved by the Institutional Animal Care and Use Committee and monitored by the Department of Laboratory Animal Resources at the University of Texas Health Science Center (San Antonio, USA).

\section{Patient consent for publication}

Not applicable.

\section{Competing interests}

The authors declare that they have no competing interests.

\section{References}

1. Siegel RL, Miller KD and Jemal A: Cancer Statistics, 2017. CA Cancer J Clin 67: 7-30, 2017.

2. Culig Z and Bartsch G: Androgen axis in prostate cancer. J Cell Biochem 99: 373-381, 2006.

3. McConnell JD: Physiologic basis of endocrine therapy for prostatic cancer. Urol Clin North Am 18: 1-13, 1991.

4. Lu J, Van der Steen T and Tindall DJ: Are androgen receptor variants a substitute for the full-length receptor? Nat Rev Urol 12: 137-144, 2015.

5. Ding Q, Motoyama J, Gasca S, Mo R, Sasaki H, Rossant J and Hui CC: Diminished Sonic hedgehog signaling and lack of floor plate differentiation in Gli2 mutant mice. Development 125: 2533-2543, 1998.

6. Motoyama J, Liu J, Mo R, Ding Q, Post M and Hui CC: Essential function of Gli2 and Gli3 in the formation of lung, trachea and oesophagus. Nat Genet 20: 54-57, 1998.

7. Ingham PW and McMahon AP: Hedgehog signaling in animal development: Paradigms and principles. Genes Dev 15: 3059-3087, 2001.

8. Marigo V, Roberts DJ, Lee SM, Tsukurov O, Levi T, Gastier JM, Epstein DJ, Gilbert DJ, Copeland NG, Seidman CE, et al: Cloning, expression, and chromosomal location of SHH and IHH: Two human homologues of the Drosophila segment polarity gene hedgehog. Genomics 28: 44-51, 1995.

9. Bitgood MJ, Shen L and McMahon AP: Sertoli cell signaling by Desert hedgehog regulates the male germline. Curr Biol 6: 298-304, 1996. 
10. Wen X, Lai CK, Evangelista M, Hongo J-A, de Sauvage FJ and Scales SJ: Kinetics of hedgehog-dependent full-length Gli3 accumulation in primary cilia and subsequent degradation. Mol Cell Biol 30: 1910-1922, 2010.

11. Ruiz i Altaba A, Palma V and Dahmane N: Hedgehog-Gli signalling and the growth of the brain. Nat Rev Neurosci 3 $24-33,2002$

12. Hutchin ME, Kariapper MST, Grachtchouk M, Wang A, Wei L, Cummings D, Liu J, Michael LE, Glick A and Dlugosz AA: Sustained Hedgehog signaling is required for basal cell carcinoma proliferation and survival: Conditional skin tumorigenesis recapitulates the hair growth cycle. Genes Dev 19 214-223, 2005

13. Sheng H, Goich S, Wang A, Grachtchouk M, Lowe L, Mo R, Lin K, de Sauvage FJ, Sasaki H, Hui CC, et al: Dissecting the oncogenic potential of Gli2: Deletion of an NH(2)-terminal fragment alters skin tumor phenotype. Cancer Res 62: 5308-5316, 2002.

14. Tojo M, Kiyosawa H, Iwatsuki K, Nakamura K and Kaneko F: Expression of the GLI2 oncogene and its isoforms in human basal cell carcinoma. Br J Dermatol 148: 892-897, 2003.

15. Regl G, Kasper M, Schnidar H, Eichberger T, Neill GW, Philpott MP, Esterbauer H, Hauser-Kronberger C, Frischauf AM and Aberger F: Activation of the BCL2 promoter in response to Hedgehog/GLI signal transduction is predominantly mediated by GLI2. Cancer Res 64: 7724-7731, 2004.

16. Regl G, Neill GW, Eichberger T, Kasper M, Ikram MS, Koller J, Hintner H, Quinn AG, Frischauf AM and Aberger F: Human GLI2 and GLI1 are part of a positive feedback mechanism in Basal Cell Carcinoma. Oncogene 21: 5529-5539, 2002.

17. Chang-Claude J, Dunning A, Schnitzbauer U, Galmbacher P, Tee L, Wjst M, Chalmers J, Zemzoum I, Harbeck N, Pharoah PD, et al: The patched polymorphism Pro1315Leu (C3944T) may modulate the association between use of oral contraceptives and breast cancer risk. Int J Cancer 103: 779-783, 2003.

18. Watkins DN, Berman DM, Burkholder SG, Wang B, Beachy PA and Baylin SB: Hedgehog signalling within airway epithelial progenitors and in small-cell lung cancer. Nature 422: 313-317, 2003.

19. Alam MM, Sohoni S, Kalainayakan SP, Garrossian M and Zhang L: Cyclopamine tartrate, an inhibitor of Hedgehog signaling, strongly interferes with mitochondrial function and suppresses aerobic respiration in lung cancer cells. BMC Cancer 16: 150, 2016

20. Stecca B and Ruiz i Altaba A: Brain as a paradigm of organ growth: Hedgehog-Gli signaling in neural stem cells and brain tumors. J Neurobiol 64: 476-490, 2005.

21. Thayer SP, di Magliano MP, Heiser PW, Nielsen CM, Roberts DJ, Lauwers GY, Qi YP, Gysin S, Fernández-del Castillo C, Yajnik V, et al: Hedgehog is an early and late mediator of pancreatic cancer tumorigenesis. Nature 425: 851-856, 2003

22. Miyazaki Y, Matsubara S, Ding Q, Tsukasa K, Yoshimitsu M, Kosai K and Takao S: Efficient elimination of pancreatic cancer stem cells by hedgehog/GLI inhibitor GANT61 in combination with mTOR inhibition. Mol Cancer 15: 49, 2016.

23. Dugum M, Hanouneh I, McIntyre T, Pai R, Aucejo F, Eghtesad B and Zein N: Sonic hedgehog signaling in hepatocellular carcinoma: A pilot study. Mol Clin Oncol 4: 369-374, 2016.

24. Syu L-J, Zhao X, Zhang Y, Grachtchouk M, Demitrack E, Ermilov A, Wilbert DM, Zheng X, Kaatz A, Greenson JK, et al: Invasive mouse gastric adenocarcinomas arising from Lgr5+ stem cells are dependent on crosstalk between the Hedgehog/GLI2 and mTOR pathways. Oncotarget 7 : 10255-10270, 2016.

25. Karhadkar SS, Bova GS, Abdallah N, Dhara S, Gardner D, Maitra A, Isaacs JT, Berman DM and Beachy PA: Hedgehog signalling in prostate regeneration, neoplasia and metastasis. Nature 431: 707-712, 2004

26. Narita S, So A, Ettinger S, Hayashi N, Muramaki M, Fazli L, Kim Y and Gleave ME: GLI2 knockdown using an antisense oligonucleotide induces apoptosis and chemosensitizes cells to paclitaxel in androgen-independent prostate cancer. Clin Cancer Res 14: 5769-5777, 2008

27. Chen M, Feuerstein MA, Levina E, Baghel PS, Carkner RD, Tanner MJ, Shtutman M, Vacherot F, Terry S, de la Taille A, et al: Hedgehog/Gli supports androgen signaling in androgen deprived and androgen independent prostate cancer cells. Mol Cancer 9: $89,2010$.
28. Sanchez P, Hernández AM, Stecca B, Kahler AJ, DeGueme AM, Barrett A, Beyna M, Datta MW, Datta S and Ruiz i Altaba A: Inhibition of prostate cancer proliferation by interference with SONIC HEDGEHOG-GLI1 signaling. Proc Natl Acad Sci USA 101: 12561-12566, 2004

29. Sheng T, Li C, Zhang X, Chi S, He N, Chen K, McCormick F, Gatalica Z and Xie J: Activation of the hedgehog pathway in advanced prostate cancer. Mol Cancer 3: 29, 2004.

30. Azoulay S, Terry S, Chimingqi M, Sirab N, Faucon H, Gil Diez de Medina S, Moutereau S, Maillé P, Soyeux P, Abbou C, et al: Comparative expression of Hedgehog ligands at different stages of prostate carcinoma progression. J Pathol 216 460-470, 2008

31. McCarthy FRK and Brown AJ: Autonomous Hedgehog signalling is undetectable in PC-3 prostate cancer cells. Biochem Biophys Res Commun 373: 109-112, 2008.

32. Zhang J, Lipinski R, Shaw A, Gipp J and Bushman W: Lack of demonstrable autocrine hedgehog signaling in human prostate cancer cell lines. J Urol 177: 1179-1185, 2007.

33. Chen M, Tanner M, Levine AC, Levina E, Ohouo P and Buttyan R: Androgenic regulation of hedgehog signaling pathway components in prostate cancer cells. Cell Cycle 8: 149-157, 2009

34. Gowda PS, Deng JD, Mishra S, Bandyopadhyay A, Liang S, Lin S, Mahalingam D and Sun LZ: Inhibition of hedgehog and androgen receptor signaling pathways produced synergistic suppression of castration-resistant prostate cancer progression. Mol Cancer Res 11: 1448-1461, 2013.

35. Lauth M and Toftgård R: Non-canonical activation of GLI transcription factors: Implications for targeted anti-cancer therapy. Cell Cycle 6: 2458-2463, 2007.

36. Wiederschain D, Wee S, Chen L, Loo A, Yang G, Huang A, Chen Y, Caponigro G, Yao YM, Lengauer C, et al: Single-vector inducible lentiviral RNAi system for oncology target validation. Cell Cycle 8: 498-504, 2009.

37. Roessler E, Ermilov AN, Grange DK, Wang A, Grachtchouk M, Dlugosz AA and Muenke M: A previously unidentified amino-terminal domain regulates transcriptional activity of wild-type and disease-associated human GLI2. Hum Mol Genet 14: 2181-2188, 2005.

38. Zhu H, Xia L, Shen Q, Zhao M, Gu X, Bouamar H, Wang B, Sun LZ and Zhu X: Differential effects of GLI2 and GLI3 in regulating cervical cancer malignancy in vitro and in vivo. Lab Invest 98: 1384-1396, 2018.

39. Kim D, Pertea G, Trapnell C, Pimentel H, Kelley R and Salzberg SL: TopHat2: accurate alignment of transcriptomes in the presence of insertions, deletions and gene fusions. Genome Biol 14: R36, 2013.

40. Anders S, Pyl PT and Huber W: HTSeq - a Python framework to work with high-throughput sequencing data. Bioinformatics 31 : $166-169,2015$.

41. Anders S and Huber W: Differential expression analysis for sequence count data. Genome Biol 11: R106, 2010.

42. Love MI, Huber W and Anders S: Moderated estimation of fold change and dispersion for RNA-seq data with DESeq2. Genome Biol 15: 550, 2014.

43. Ritchie ME, Phipson B, Wu D, Hu Y,Law CW, Shi W and Smyth GK: limma powers differential expression analyses for RNA-sequencing and microarray studies. Nucleic Acids Res 43: e47, 2015.

44. Huang W, Sherman BT and Lempicki RA: Systematic and integrative analysis of large gene lists using DAVID bioinformatics resources. Nat Protoc 4: 44-57, 2009.

45. Huang W, Sherman BT and Lempicki RA: Bioinformatics enrichment tools: Paths toward the comprehensive functional analysis of large gene lists. Nucleic Acids Res 37: 1-13, 2009.

46. Livak KJ and Schmittgen TD: Analysis of relative gene expression data using real-time quantitative PCR and the $2-\Delta \Delta C T$ method. Methods 25: 402-408, 2001.

47. National Research Council (US) Committee for the Update of the Guide for the Care and Use of Laboratory Animals: Guide for the Care and Use of Laboratory Animals. 8th edition. National Academies Press (US), Washington, DC, 2011.

48. Holzbeierlein J, Lal P, LaTulippe E, Smith A, Satagopan J, Zhang L, Ryan C, Smith S, Scher H, Scardino P, et al: Gene expression analysis of human prostate carcinoma during hormonal therapy identifies androgen-responsive genes and mechanisms of therapy resistance. Am J Pathol 164: 217-227, 2004.

49. Taylor BS, Schultz N, Hieronymus H, Gopalan A, Xiao Y, Carver BS, Arora VK, Kaushik P, Cerami E, Reva B, et al: Integrative genomic profiling of human prostate cancer. Cancer Cell 18: 11-22, 2010 
50. Jin RJ, Wang Y, Masumori N, Ishii K, Tsukamoto T, Shappell SB Hayward SW, Kasper S and Matusik RJ: NE-10 neuroendocrine cancer promotes the $\mathrm{LNCaP}$ xenograft growth in castrated mice. Cancer Res 64: 5489-5495, 2004.

51. Antonarakis ES, Lu C, Wang H, Luber B, Nakazawa M, Roeser JC, Chen Y, Mohammad TA, Chen Y, Fedor HL, et al: AR-V7 and resistance to enzalutamide and abiraterone in prostate cancer. N Engl J Med 371: 1028-1038, 2014.

52. Lu C and Luo J: Decoding the androgen receptor splice variants. Transl Androl Urol 2: 178-186, 2013.

53. Gregory CW, He B, Johnson RT, Ford OH, Mohler JL, French FS and Wilson EM: A mechanism for androgen receptor-mediated prostate cancer recurrence after androgen deprivation therapy. Cancer Res 61: 4315-4319, 2001.

54. Li N, Chen M, Truong S, Yan C and Buttyan R: Determinants of Gli2 co-activation of wildtype and naturally truncated androgen receptors. Prostate 74: 1400-1410, 2014.
55. Hu R,Dunn TA, Wei S, Isharwal S, Veltri RW,Humphreys E,Han M, Partin AW, Vessella RL, Isaacs WB, et al: Ligand-independent androgen receptor variants derived from splicing of cryptic exons signify hormone-refractory prostate cancer. Cancer Res 69: 16-22, 2009.

56. Liu LL, Xie N, Sun S, Plymate S, Mostaghel E and Dong X: Mechanisms of the androgen receptor splicing in prostate cancer cells. Oncogene 33: 3140-3150, 2014

(i) (9) This work is licensed under a Creative Commons Attribution-NonCommercial-NoDerivatives 4.0 International (CC BY-NC-ND 4.0) License. 